\title{
Landiolol, esmolol and propranolol protect from ischemia/reperfusion injury in isolated guinea pig hearts
}

\author{
[Le landiolol, l'esmolol et le propranolol protègent des lésions résultant de \\ l'ischémie/reperfusion dans des caurs de cobaye isolés]
}

Saori Kurosawa MD, Noriaki Kanaya MD PhD, Yukitoshi Niiyama MD, Masayasu Nakayama MD PhD, Satoshi Fujita MD PhD, Akiyoshi Namiki MD PhD

Purpose: Beta blockers are thought to exert beneficial effects on the ischemic heart. The authors examined the effects of landiolol (ONO I IOI), a highly selective BI antagonist, propranolol, a nonspecific $ß$ blocker, and esmolol, a selective $ß \mid$ antagonist, on postischemic contractile recovery. Drugs were given prophylactically.

Methods: Ischemia-reperfusion in isolated guinea pig hearts was induced by stopping the perfusion for $45 \mathrm{~min}$ and reperfusing for 60 min. Hearts ( $n=7$ in each group) were treated with or without propranolol (I or $10 \mu \mathrm{M}$ ), esmolol (5 or $50 \mu \mathrm{M}$ ), or landiolol (20, 100 or $500 \mu \mathrm{M}$ ) ten minutes before inducing ischemia.

Results: At the end of reperfusion, left ventricular pressure (LVP) recovered to $64 \pm 3 \%$ of the baseline value in the control group. With I and $10 \mu \mathrm{M}$ propranolol, LVP recovered to $90 \pm 5 \%$ and $100 \pm 6 \%$ of the baseline value at $60 \mathrm{~min}$ after reperfusion, respectively. Fifty $\mu \mathrm{M}$ but not $5 \mu \mathrm{M}$ of esmolol resulted in restoration of LVP to $97 \pm 17 \%$ of the pre-ischemic value at 60 min after reperfusion. In hearts pretreated with 100 and $500 \mu \mathrm{M}$ landiolol, LVP was restored to $109 \pm 5 \%$ and $104 \pm 5 \%$ of the baseline value, respectively. Landiolol $100 \mu \mathrm{M}$ did not depress LVP in the pre-ischemic period.

Conclusions: The present study shows that landiolol, an ultrashort-acting cardioselective ß। blocker, has cardioprotective effects on ischemia-reperfusion injury in isolated guinea pig hearts. All three $B$ blockers were equally protective but the intermediate dosage of landiolol preserved LVP during the pre-ischemic period.
Objectif : On croit que les bêtabloquants ont des effets bénéfiques sur le cœur ischémique. Les auteurs ont vérifié les effets du landiolol (ONO I I O I), un antagoniste BI hautement sélectif, du propranolol, un $B$ bloquant non spécifique, et de l'esmolol, un antagoniste Bl sélectif, sur la récupération contractile postischémique. Les médicaments ont été administrés préventivement.

Méthode : L'ischémie-reperfusion a été induite dans des cœurs de cobaye isolés en stoppant la perfusion pendant 45 min et en reperfusant pendant $60 \mathrm{~min}$. Les cœurs ( $n=7$ dans chaque groupe) ont été traités avec ou sans propranolol ( I ou $10 \mu \mathrm{M}$ ), esmolol (5 ou $50 \mu \mathrm{M}$ ) ou landiolol (20, 100 ou 500 MM) dix minutes avant l'induction de l'ischémie.

Résultats : À la fin de la reperfusion, la pression ventriculaire gauche (PVG) avait retrouvé $64 \pm 3 \%$ de sa valeur de base dans le groupe témoin. Avec I et $10 \mu \mathrm{M}$ de propranolol, la PVG a été récupérée respectivement à $90 \pm 5 \%$ et $100 \pm 6 \%$, 60 min après la reperfusion. La dose de $50 \mu \mathrm{M}$, non celle de $5 \mu \mathrm{M}$, d'esmolol a été suivie de la restauration de la PVG à $97 \pm 17 \%$ de la valeur préischémique, 60 min après la reperfusion. Dans les cœurs prétraités avec 100 et $500 \mu \mathrm{M}$ de landiolol, la PVG a été restaurée à $109 \pm 5 \%$ et à 104 $\pm 5 \%$ de sa valeur de base, respectivement. La dose de $100 \mu \mathrm{M}$ de landiolol n'a pas causé de baisse de la PVG en période préischémique.

Conclusion : La présente étude montre que le landiolol, un BI bloquant cardiosélectif à action très brève, a des effets cardioprotecteurs sur les lésions résultant de l'ischémie-reperfusion dans des cœurs de cobaye isolés. Les trois $\beta$ bloquants ont été également protecteurs, mais la dose intermédiaire de landiolol a diminué la PVG pendant la période préischémique.

From the Department of Anesthesiology, Sapporo Medical University School of Medicine, Sapporo, Japan.

Address correspondence to: Dr. Noriaki Kanaya, Department of Anesthesiology, Sapporo Medical University, School of Medicine, S-1, W-16, Chuo-ku, Sapporo 060-8543, Japan. Phone: +81-11-611-2111; Fax: +81-11-631-9683; E-mail: kanaya@sapmed.ac.jp

This study was supported in part by Grant-in-Aid No. C-12671487 from the Japan Society of the Promotion of Science, Tokyo, Japan. Presented in part at the Annual Meeting of the American Society of Anesthesiologists, New Orleans, Louisiana, October 13-17, 2001. Accepted for publication November 28, 2002.

Revision accepted February 13, 2003. 
$\mathrm{L}$

ANDIOLOL hydrochloride (ONO-1101) is a newly developed highly cardioselective $B$ blocker with a potency ratio $(B 1 / B 2)$ of 255 , compared with 33 for esmolol and 0.68 for propranolol. ${ }^{1}$ Although this agent is more potent than esmolol as a $B$-antagonist, ${ }^{1,2}$ the cardiodepressant effect of landiolol is less than that of esmolol. ${ }^{3}$ In addition, it has a short duration (half-life of four minutes) of activity, enabling rapid recovery after cessation of administration by rapid hydrolysis of its ester link. ${ }^{1}$ It has neither intrinsic sympathomimetic activity nor significant membrane-stabilizing activity. ${ }^{1}$

Beta adrenoceptor blocking agents have been shown to have cardioprotective effects on ischemic and hypoxic hearts, including attenuation of arrhythmias, ${ }^{4}$ improvement in ventricular function, and an overall decrease in mortality in patients with ischemic heart disease. ${ }^{5,6}$ Beta adrenoceptor blockers have also been used as an alternative to cardioplegic arrest during coronary artery bypass surgery to reduce ischemic damage. ${ }^{7,8}$ Although the exact mechanisms by which cardioprotective agents act are not yet fully understood, $\beta$ blockers are thought to exert beneficial effects on the ischemic heart by lowering myocardial oxygen consumption as a consequence of reduced contractility and heart rate (HR). ${ }^{9}$ Their beneficial effects are also thought to be due to their antioxidant ${ }^{10-12}$ and, in the case of propranolol, membrane-stabilizing ${ }^{13}$ properties. Recently, $\beta$ blockers have also been reported to preserve the sarcoplasmic reticular (SR) function and gene expression in ischemia-reperfusion (I/R) rat hearts. ${ }^{14}$ These findings suggest that $\beta$ blockers would be beneficial for the treatment of I/R-induced myocardial injury.

Although the cardioprotective effects of propranolol and esmolol are well known, the effects of landiolol on contractility in hearts subjected to $\mathrm{I} / \mathrm{R}$ are not well known. The purpose of this study was 1 ) to determine the cardioprotective effects of landiolol on functional recovery in isolated guinea pig hearts subjected to I/R, and 2) to compare the effects of landiolol (a ßI-specific blocker), propranolol (a nonspecific $ß$ blocker) and esmolol (a ßl-specific blocker) on functional recovery in isolated guinea pig hearts subjected to $\mathrm{I} / \mathrm{R}$.

\section{Materials and methods \\ Preparation and measurements}

This investigation conformed to the guidelines for care and use of laboratory animals published by the National Institutes of Health and was approved by our institutional Animal Care Committee. As described previously, ${ }^{15}$ male English short-haired guinea pigs (250-300 g) received ip ketamine $20 \mathrm{mg}$ and 1,000 $\mathrm{U}$ of heparin and were decapitated after they had become unresponsive to noxious stimulation. After thoracotomy, the inferior and superior vena cava were sectioned and the aorta was cannulated distal to the aortic valve. Each heart was perfused in a retrograde fashion via the aorta with a cold oxygenated, modified Krebs-Ringer's solution equilibrated with $95 \%$ oxygen and $5 \%$ carbon dioxide and was then rapidly excised. Perfusate was disk-filtered $(5 \mu$ bore size $)$ in-line and had the following composition (in $\mathrm{mM}$ ): 137 $\mathrm{Na}^{+}, 5 \mathrm{~K}^{+}, 1.2 \mathrm{Mg}^{+}, 2.5 \mathrm{Ca}^{2+}, 134 \mathrm{Cl}^{-}, 15.5 \mathrm{HCO}_{3}^{-}, 1.2$ $\mathrm{H}_{2} \mathrm{PO}_{4}, 11.5$ glucose, 2 pyruvate, 16 mannitol, and 0.05 ethylene-diamine-tetraacetic acid. Perfusate and bath temperatures were maintained at $37^{\circ} \mathrm{C}$ by a thermostatically controlled water circulator (Thermo pump $^{\mathrm{TM}}$, Taitec CO., Koshiya, Japan). Isovolemic development (systolic-diastolic) of left ventricular pressure (LVP), spontaneous atrial HR, and aortic inflow, which indicates coronary inflow $(\mathrm{CF})$, were measured continuously. LVP was measured by using a pressure transducer (DTX Plus Press ${ }^{\mathrm{TM}}$, Ohmeda, WI, USA) connected to a thin, saline-filled latex balloon (LB-3 ${ }^{\mathrm{TM}}$, MARS Inc., Sapporo, Japan) inserted into the left ventricle (LV) through the left atrium. Balloon volume was adjusted to maintain a diastolic LVP of $0 \mathrm{mmHg}$ during the initial control period so that any increase in diastolic LVP reflected an increase in left ventricular wall stiffness or diastolic contracture. The volume of the balloon was unchanged during the experiment. CF (aortic) was measured continuously at a constant temperature and at a normal aortic perfusion (gravity) pressure of $55 \mathrm{mmHg}$ by a transit-time, self-calibrating, in-line ultrasonic flowmeter (Research Flowmeter Transonic T106X; Transonic System, Ithaca, NY, USA) placed directly into the aortic inflow line.

Hearts were perfused with Krebs-Ringer's solution for a 15-min stabilization period. After pre-ischemic measurement of cardiac function, hearts $(n=7$ in each group) were treated with propranolol ( 1 and $10 \mu \mathrm{M})$, esmolol (5 and $50 \mu \mathrm{M}$ ), landiolol hydrochloride (ONO-1101; 20, 100, and $500 \mu \mathrm{M}$ ) or no $\beta$ blocker (control group) for ten minutes. Each $\beta$ blocker was infused just above the perfusion cannula. The heart was then subjected to $45 \mathrm{~min}$ of global ischemic arrest at $37^{\circ} \mathrm{C}$ by clamping the aortic cannula. Finally, the hearts were reperfused for $60 \mathrm{~min}\left(37^{\circ} \mathrm{C}\right)$ for postischemic functional measurement. Cardiac mechanical function was estimated as LVP, HR, CF and rate-pressure product $(\mathrm{RPP} ; \mathrm{LVP} \times \mathrm{HR})$. In the preliminary experiments, $45 \mathrm{~min}$ of ischemia followed by $60 \mathrm{~min}$ of reperfusion were sufficient to produce a decrease in LVP to $72 \pm 5 \%$ of the pre-ischemic value.

Landiolol and esmolol were donated by Ono Pharmaceutical Co., Ltd. (Osaka, Japan) and Maruishi 
Pharmaceutical Co., Ltd. (Osaka, Japan), respectively. Propranolol was purchased from Sigma Chemical Co. (St. Louis, USA).

\section{Statistical analysis}

Results are expressed as means \pm SEM. To determine differences in recovery of function between the groups, data were subjected to analysis of variance with repeated measures. Post hoc analyses were performed with Fisher's protected least significant difference test. The relationship between myocardial depressant effects of $\beta$-blockers and post-ischemic recovery in LVP was evaluated with analysis of covariance. A $P$ value of less than 0.05 was considered statistically significant. The main results are summarized in the text and in the Figure.

\section{Results}

A Table showing the effects of propranolol, esmolol and landiolol on LVP, HR, RPP and CF is available as additional material on the Journal's web site at www.cja-jca.org. Although pretreatment with the lowest doses of $\beta$-blockers showed no myocardial depression, the highest doses of $B$-blockers showed profound myocardial depression.

After $60 \mathrm{~min}$ of reperfusion, LVP was restored to $64 \pm 1 \%, 64 \pm 3 \%$, and $64 \pm 3 \%$ of the baseline value in the propranolol, esmolol, and landiolol groups without $B$-blockers, respectively (Figure). In hearts pretreated with 1 and $10 \mu \mathrm{M}$ propranolol, LVP was restored to $90 \pm 5 \%$ and $100 \pm 6 \%$ of baseline value, respectively. After $60 \mathrm{~min}$ of reperfusion, HR was restored to $125 \pm 12 \%, 94 \pm 6 \%$ and $94 \pm 5 \%$ of the baseline value in the control, $1 \mu \mathrm{M}$ and $10 \mu \mathrm{M}$ propranolol group, respectively. The magnitudes of $\mathrm{HR}$ recovery from the corresponding pre-ischemic values were not significantly different from that in the control group. After $60 \mathrm{~min}$ of reperfusion, CF was restored to $86 \pm 5 \%, 92 \pm 4 \%$ and $65 \pm 7 \%$ of the baseline value in the control, $1 \mu \mathrm{M}$ and $10 \mu \mathrm{M}$ propranolol group, respectively.

In hearts pretreated with $50 \mu \mathrm{M}$ esmolol, LVP was restored to $97 \pm 24 \%$ of the baseline value. However, $5 \mu \mathrm{M}$ esmolol caused no significant change in LVP at 60 min after reperfusion compared with that in the control group. After pretreatment with $50 \mu \mathrm{M}$ esmolol, RPP decreased to $75 \pm 7 \%$ of the baseline value, and improved $60 \mathrm{~min}$ after reperfusion (Table). After $60 \mathrm{~min}$ of reperfusion, HR was restored to 113 $\pm 17 \%, 98 \pm 21 \%$ and $135 \pm 20 \%$ of the baseline value in the control, 5 and $50 \mu \mathrm{M}$ esmolol group, respectively. There was no significant difference in the magnitude of recovery in $\mathrm{HR}$ at $60 \mathrm{~min}$ after reperfusion

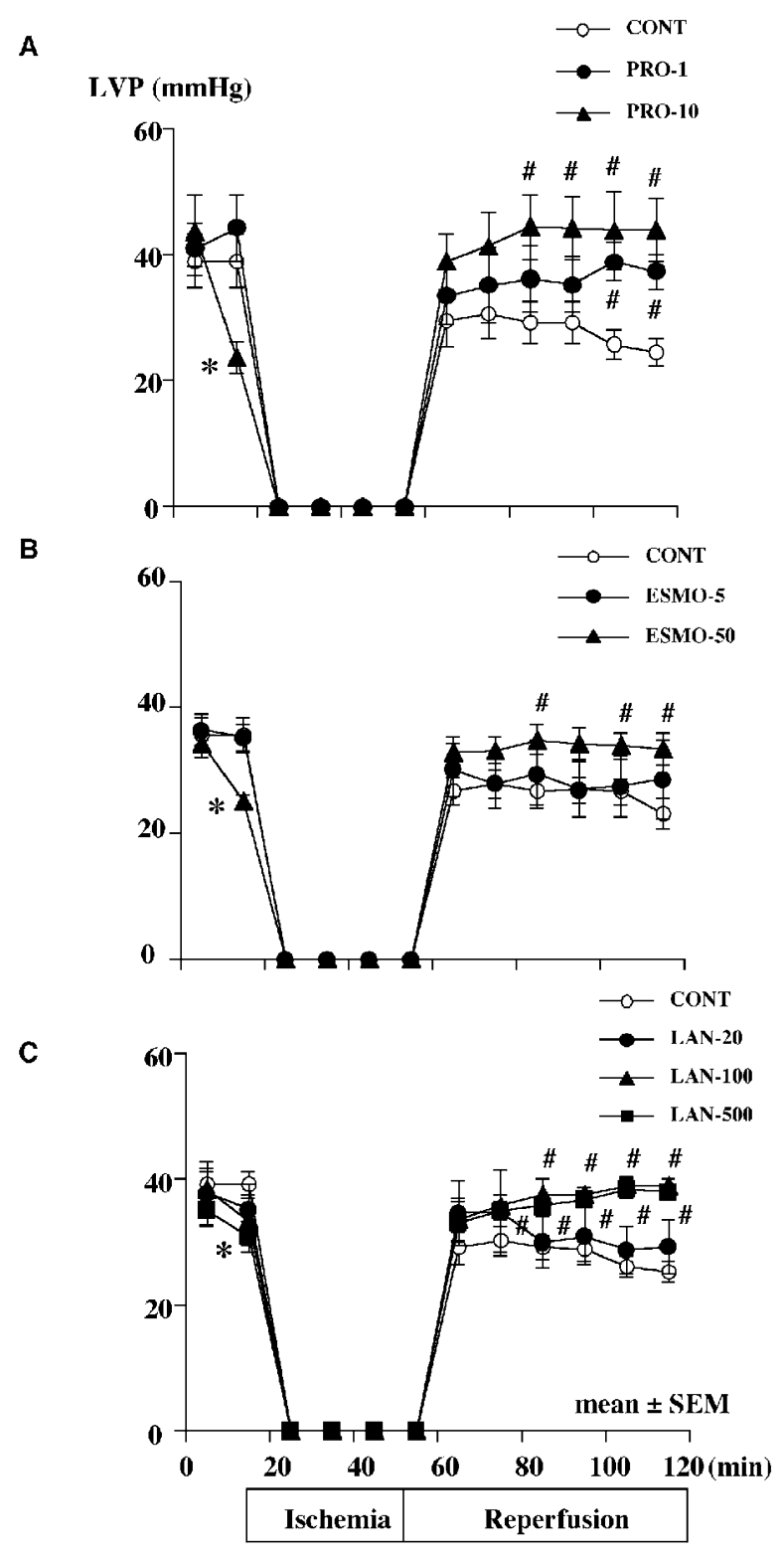

FIGURE Time course of left ventricular pressure (LVP) before, during, and after global ischemia in propranolol (PRO; A), esmolol $($ ESMO; B $)$, and landiolol $(\mathrm{LAN} ; \mathrm{C})$ groups. $\mathrm{CONT}=$ control group. Values are expressed as mean \pm SEM. ${ }^{*} P<0.05$ vs corresponding baseline value; $\# P<0.05$ vs control group. $n=7$ in each group.

among the groups. After $60 \mathrm{~min}$ of reperfusion, $\mathrm{CF}$ was restored to $85 \pm 7 \%, 94 \pm 11 \%$ and $97 \pm 6 \%$ of the pre-ischemic value in the control, 5 and $50 \mu \mathrm{M}$ esmolol group, respectively. 
After $60 \mathrm{~min}$ of reperfusion, LVP was restored to 64 $\pm 3 \%, 109 \pm 5 \%$ and $104 \pm 5 \%$ of the baseline value in the control, 100 and $500 \mu \mathrm{M}$ landiolol group, respectively. However, $20 \mu \mathrm{M}$ landiolol did not significantly improve postischemic recovery in LVP. Only $500 \mu \mathrm{M}$ landiolol caused a significant decrease in RPP at ten minutes after drug administration, and showed a profound recovery $60 \mathrm{~min}$ after reperfusion. After $60 \mathrm{~min}$ of reperfusion, HR was restored to $122 \pm 17 \%, 118 \pm$ $4 \%, 107 \pm 12 \%$ and $118 \pm 14 \%$ of the baseline value in the control, 20, 100 and $500 \mu \mathrm{M}$ landiolol group, respectively. There was no significant difference in the magnitudes of recovery in HR at 60 min after reperfusion among the four groups. After $60 \mathrm{~min}$ of reperfusion, $\mathrm{CF}$ was restored to $85 \pm 7 \%, 90 \pm 4 \%, 88 \pm 4 \%$ and $94 \pm 5 \%$ of the baseline value in the control, 20,100 and $500 \mu \mathrm{M}$ landiolol group, respectively. There was no significant difference in the magnitudes of restoration in $\mathrm{CF}$ among the four groups.

\section{Discussion}

The present study shows that landiolol hydrochloride, an ultra-short-acting cardioselective $B$ blocker, as well as propranolol and esmolol, have cardioprotective effects on $\mathrm{I} / \mathrm{R}$ injury in isolated guinea pig hearts. Low doses of propranolol $(1 \mu \mathrm{M})$, esmolol $(5 \mu \mathrm{M})$ and landiolol $(20 \mu \mathrm{M})$ were not sufficient to elicit cardioprotective effects in this model. Pretreatment with $10 \mu \mathrm{M}$ propranolol, $50 \mu \mathrm{M}$ esmolol, and 100 and 500 $\mu \mathrm{M}$ landiolol improved myocardial contractility after a transient period of ischemia, but the highest doses of propranolol $(10 \mu \mathrm{M})$, esmolol $(50 \mu \mathrm{M})$ and landiolol $(500 \mu \mathrm{M})$ caused significant myocardial depression before ischemia. Landiolol at a dose of $100 \mu \mathrm{M}$ caused no significant myocardial depression before ischemia while improving postischemic functional recovery.

The effectiveness of $B$-adrenoceptor blockade in patients with ischemic heart disease has been demonstrated. ${ }^{5,6}$ Wallace et $a l^{6}$ reported that perioperative administration of atenolol reduced the incidence of cardiac events in a randomized, double-blinded, placebocontrolled study. They found that perioperative atenolol given for one week after the operation to patients at high risk for coronary artery disease reduced the incidence of postoperative myocardial ischemia and the risk of death at two years. HR before an episode of ischemia and during the entire postoperative week were lower in the atenolol group. Such pre-ischemic energy sparing effects, due to depression of cardiodynamic function, have been suggested as mechanisms by which ß blockers provide postischemic functional recovery of the myocardium. ${ }^{16}$ However, the cardioprotective effects cannot only be explained by energy-sparing mechanisms in the pre-ischemic period. ${ }^{13}$ In fact, Wallace et al. ${ }^{6}$ found that $15 \%$ or more of ischemic episodes are independent of HR. In the present study, landiolol $(100 \mu \mathrm{M})$ had a protective effect on the myocardium subjected to $\mathrm{I} / \mathrm{R}$ without causing a reduction in RPP in the pre-ischemic period. These findings suggest that $B$-adrenoceptor blockers may exert antiischemic effects independent of cardiac work.

Another possible mechanism underlying the antiischemic effects of $\beta$-adrenoceptor blockers is myocardial protection from ischemia-induced excess release of norepinephrine. Most cardiac $B$-adrenergic receptors are of the Bl-receptor subtype. Beta receptors are situated on the outer surface of the sarcolemma and are coupled to adenyl cyclase by the stimulatory guanine nucleotide-binding protein. The major intracellular effects of $\beta$ agonists are elicited by formation of cyclic adenosine monophosphate (AMP), which increases the activity of cyclic AMP-dependent protein kinase A. The latter phosphorylates various proteins, including calcium channels. Acute myocardial ischemia leads to a gradual increase in $B$-adrenergic receptors. This increase occurs rapidly after the onset of global ischemia (15 min) and persists even after prolonged periods of global ischemia. ${ }^{17}$ In normal hearts, high catecholamine levels induce receptor desensitization with internalization of $B$-adrenergic receptors. In acute myocardial ischemia, however, agonist-promoted internalization and functional uncoupling of $B$-adrenergic receptors are abolished. Consequently, the balance of internalization and externalization of receptors is shifted towards an increase in functionally coupled receptors at the cell surface. ${ }^{17}$ The above-mentioned events lead to the overload of intracellular free calcium ions, which may contribute to myocyte injury. ${ }^{18}$ If $B$-blockers exert their anti-ischemic effect mainly by blocking the BIreceptor, postischemic contractile function should recover in order of $B 1$ receptor blocking potency. However, in the present study, the three $\beta$ blockers showed similar effects on postischemic recovery in spite of differences in $ß 1$-blocking potency. Therefore, it is unlikely that their anti-ischemic effect depends only on B1-receptor subtype blocking potency.

Beta-adrenoceptor blockers are believed to have some direct effects on the myocardial membrane, ${ }^{13,19}$ antiperoxidative activity, ${ }^{10}$ antiradical effect, ${ }^{20}$ sarcoplasmic reticular (SR) function, ${ }^{14}$ and cardiac SR gene expression. ${ }^{14}$ Propranolol, a non-specific $B$ adrenoceptor blocker, has been reported to have a cardioprotective effect via several actions, such as membrane-stabilizing activity ${ }^{13}$ and inhibition of the enzyme NADH oxidase, ${ }^{21}$ and/or higher lipophilic 
property. ${ }^{22}$ Propranolol induced better LVP recovery in rat ischemic-reperfused hearts than did atenolol, a ß1-specific blocker. ${ }^{14}$ Propranolol caused marked myocardial depression in our model, whereas the same dose of propranolol had no effect on cardiac performance in the rat. ${ }^{14}$ This may be due to differences in experimental models and species. Esmolol, a ß1-specific blocker, has also been reported to exert a cardioprotective effect during myocardial I/R. Several studies have suggested that esmolol could be used effectively as an adjunct to cardioplegic solution for induction and maintenance of cardiac arrest during cardiac surgery. ${ }^{7}$ Modulation of free-radical-mediated reaction and arachidonic acid metabolism ${ }^{11}$ and inhibition of neutrophil superoxide generation and platelet aggregation $^{12}$ have been postulated as cellular mechanisms underlying esmolol-induced myocardial protection. While this could be true in vivo, it does not apply to the present study, which was performed in bufferperfused hearts. Further investigation is needed to compare these cellular mechanisms of $\beta$-adrenoceptor blockers underlying myocardial protection.

We investigated the effect of landiolol on cardiac performance during I/R. Yasuda $e t a l^{8}$ reported that landiolol has the potential to enhance postischemic cardiac function after warm cardioplegic arrest in isolated rat hearts. They infused a crystalloid cardioplegic solution $\left(37^{\circ} \mathrm{C}\right)$ with landiolol $\left(1,2.5,5\right.$ or $\left.10 \mathrm{mmol} \cdot \mathrm{L}^{-1}\right)$ to the coronary artery and then subjected the heart to $30 \mathrm{~min}$ of ischemic arrest followed by $40 \mathrm{~min}$ of reperfusion. They observed a significant improvement in postischemic recovery of aortic flow only when $2.5 \mathrm{mmol} \cdot \mathrm{L}^{-1}$ of landiolol was used. Although their results are in agreement with ours on the cardioprotective effect of landiolol, the effective doses in their study are more than tenfold higher than those used in our study. This may be due to differences in experimental models and species. In the present study, landiolol $(100 \mu \mathrm{M})$ had a protective effect on the myocardium subjected to $\mathrm{I} / \mathrm{R}$ without causing a reduction in RPP in the pre-ischemic period. These findings suggest that the cardioprotective effect of landiolol cannot be explained only by energysparing mechanisms in the pre-ischemic period. However, landiolol has neither intrinsic sympathomimetic activity nor significant membrane-stabilizing activity. ${ }^{1}$ In in vitro experiments, landiolol and esmolol failed to inhibit human neutrophil function, including reactive oxygen species production. ${ }^{23}$ It is not known to what extent the cardioprotective effect of landiolol is due to antioxidation such as that seen with propranolol; further investigation is needed.

A limitation of this study is that the doses of $\beta$ blockers were not equipotent with BI-receptor sub- type blocking potency. Although landiolol is reported to be more potent than esmolol as a $B$-blocker, ${ }^{1,2}$ it is also reported that the cardiodepressant effect of landiolol is less than that of esmolol. ${ }^{3}$ It is most likely that differences in pre-ischemic hemodynamics lead to differences in postischemic recovery. We chose the doses of $\beta$ blockers based on their cardiodepressant effects instead of their $ß 1$-adrenoceptor blocking potency. Because landiolol is not approved for clinical use, the clinical relevance of our study remains hypothetical. Our study was carried out only to clarify whether landiolol might have cardioprotective effects. Based on our findings, further research should determine if landiolol is advantageous in reducing myocardial damage after $\mathrm{I} / \mathrm{R}$ injury in the perioperative period.

In conclusion, the present study shows that landiolol hydrochloride, an ultra-short-acting cardioselective $\beta$ blocker, as well as propranolol and esmolol, have cardioprotective effects on I/R injury in isolated guinea pig hearts. The cardioprotective effect of landiolol cannot be explained only by a reduction in cardiac work in the pre-ischemic period. The mechanisms responsible for the cardioprotective effect of landiolol against $\mathrm{I} / \mathrm{R}$ injury remain to be determined.

\section{References}

1 Iguchi S, Iwamura $H$, Nishizaki $M$, et al. Development of a highly cardioselective ultra short-acting ß-blocker, ONO-1101. Chem Pharm Bull 1992; 40: 1462-9.

2 Muraki K, Nakagawa H, Nagano N, et al. Effects of ONO-1101, a novel beta-antagonist, on action potential and membrane currents in cardiac muscle. J Pharmacol Exp Ther 1996; 278: 555-63.

3 Sasao J, Tarver SD, Kindscher JD, Taneyama C, Benson $K T$, Goto $H$. In rabbits, landiolol, a new ultra-shortacting $B$-blocker, exerts a more potent negative chronotropic effect and less effect on blood pressure than esmolol. Can J Anesth 2001; 48: 985-9.

4 Lubbe WF, Podzuweit T, Opie LH. Potential arrhythmogenic role of cyclic adenosine monophosphate (AMP) and cytosolic calcium overload: implications for prophylactic effects of beta-blockers in myocardial infarction and proarrhythmic effects of phosphodiesterase inhibitors. J Am Coll Cardiol 1992; 19: 1622-33.

5 Anonymous. Randomised trial of intravenous atenolol among 16027 cases of suspected acute myocardial infarction: ISIS-1. First International Study of Infarct Survival Collaborative Group. Lancet 1986; 2: 57-66.

6 Wallace A, Layug B, Tateo I, et al. Prophylactic atenolol reduces postoperative myocardial ischemia. McSPI Research Group. Anesthesiology 1998; 88: 7-17.

7 Mehlhorn U. Improved myocardial protection using continuous coronary perfusion with normothermic 
blood and beta-blockade with esmolol. Thorac

Cardiovasc Surg 1997; 45: 224-31.

8 Yasuda T, Kamiya H, Tanaka $\Upsilon$, Watanabe G. Ultrashort-acting cardioselective beta-blockade attenuates postischemic cardiac dysfunction in the isolated rat heart. Eur J Cardiothorac Surg 2001; 19: 647-52.

9 Gross GJ, Buch JD, Warltier DC, Hardman HF. Role of autoregulation in the beneficial action of propranolol on ischemic blood flow distribution and stenosis severity in the canine myocardium. J Pharmacol Exp Ther 1982; 222: 635-40.

10 Mak IT, Weglicki WB. Protection by ß-blocking agents against free radical-mediated sarcolemmal lipid peroxidation. Circ Res 1988; 63: 262-6.

11 Roth E, Torok B. Effect of the ultrashort-acting Bblocker Brevibloc on free-radical-mediated injuries during the early reperfusion state. Basic Res Cardiol 1991; 86: 422-33.

12 Roth E, Matos G, Guarnieri C, Papp B, Varga J. Influence of the beta-blocker therapy on neutrophil superoxide generation and platelet aggregation in experimental myocardial ischemia and reflow. Acta Physiol Hung 1995; 83: 163-70.

13 Takeo S, ramada H, Tanonaka K, Hayashi $M$, Sunagawa N. Possible involvement of membrane-stabilizing action in beneficial effect of beta adrenoceptor blocking agents on hypoxic and posthypoxic myocardium. J Pharmacol Exp Ther 1990; 254: 847-56.

14 Temsah RM, Dyck C, Netticadan T, Chapman D, Elimban V, Dhalla NS. Effect of $B$-adrenoceptor blockers on sarcoplasmic reticular function and gene expression in the ischemic-reperfused heart. J Pharmacol Exp Ther 2000; 293: 15-23.

15 Nakae $\Upsilon$, Fujita $S$, Namiki A. Isoproterenol enhances myofilament $\mathrm{Ca}^{2+}$ sensitivity during hypothermia in isolated guinea pig beating hearts. Anesth Analg 2001; 93: 846-52.

16 Ichibara $K$, Abiko $\Upsilon$. Effects of diltiazem and propranolol on irreversibility of ischemic cardiac function and metabolism in the isolated perfused rat heart. J

Cardiovasc Pharmacol 1983; 5: 745-51.

17 Strasser RH, Marquetant R, Kübler W. Adrenergic receptors and sensitization of adenylyl cyclase in acute myocardial ischemia. Circulation 1990; 82(Suppl II): II23-9.

18 Tani M. Mechanisms of $\mathrm{Ca}^{2+}$ overload in reperfused ischemic myocardium. Annu Rev Physiol 1990; 52: 543-59.

19 Dhalla KS, Rupp H, Beamish RE, Dhalla NS. Mechanisms of alterations in cardiac membrane $\mathrm{Ca}^{2+}$ transport due to excess catecholamines. Cardiovasc Drugs Ther 1996; 10: 231-8.

20 Khaper N, Rigatto C, Seneviratne C, Li T, Singal PK.
Chronic treatment with propranolol induces antioxidant changes and protects against ischemia-reperfusion injury. J Mol Cell Cardiol 1997; 29: 3335-44.

21 Sakurada A, Voss DO, Brandao D, Campello AP. Effects of propranolol on heart muscle mitochondria. Biochem Pharmacol 1972; 21: 535-40.

22 Liu X, Engelman RM, Agrawal HR, Das DK. Preservation of membrane phospholipids by propranolol, pindolol, and metoprolol: a novel mechanism of action of beta-blockers. J Mol Cell Cardiol 1991; 23: 1091-100.

23 Nishina K, Akamatsu H, Mikawa K, Shiga M, Obara $H$, Niwa $\Upsilon$. A comparison of atenolol, labetalol, esmolol, and landiolol for altering human neutrophil functions. Anesth Analg 2001; 93: 641-4. 